\title{
Hubungan Motion Graphic Sebagai Konten Promosi Sekolah di Media Sosial
}

\author{
Muhamad Rendi Nurmansyah, Ike Atikah Ratnamulyani, Ali Alamsyah \\ Kusumadinata \\ Program studi Sains Komunikasi, Fakultas Ilmu Sosial Dan Ilmu Politik, \\ Universitas Djuanda Bogor \\ Email: rendy.nurmansyah@live.com, ikea.ratnamulyani@gmail.com, \\ alialamsyahkusumadinata@gmail.com
}

\begin{abstract}
Social media is one product of the development of technology wrote so rapidly. Social media can not be separated from the everyday human life, seen from the users of social media continues to grow every time. Various convenience perceived as benefits of social media in life. As the utilization of social media as a means of information dissemination promotion of a company or agency. Motion graphic is one form of digital content that are frequently exploited by an agency or company for delivery of broad information such as public service announcements, company profile, and media promotion. Social media can be utilized as dispersion media motion graphic content more broadly and efficiently.
\end{abstract}

Keywords: Motion Graphic, Animation, Social Media, Promotion

\begin{abstract}
ABSTRAK
Media sosial merupakan salah satu produk dari hasil perkembangan teknologi yg begitu pesat. Media sosial tidak dapat dipisahkan dari kehidupan manusia seharihari, terlihat dari jumlah pengguna sosial media yang terus bertambah disetiap waktunya. Berbagai kemudahan dirasakan sebagai manfaat dari adanya media sosial dalam kehidupan. Seperti pemanfaatan media sosial sebagai alat penyebaran informasi promosi suatu instansi atau perusahaan. Motion graphic merupakan salah satu bentuk konten digital yang sering dimanfaatkan oleh suatu instansi atau perusahaan untuk penyampaian informasi yang bersifat luas seperti iklan layanan masyarakat, company profile, dan media promosi. Media sosial dapat dimanfaatkan sebagai media penyebaran konten motion graphic secara lebih luas dan efisien.
\end{abstract}

Keywords: Motion Graphic, Animasi, Media Sosial, Promosi.

\section{Pendahuluan}

Seiring dengan semakin majunya teknologi dalam berkomunikasi membawa implikasi yang tidak sedikit kepada manusia. Implikasi ini berkaitan 
erat dengan hubungan antar manusia dalam komunikasi yang menurut Littlejohn dan Karen (2014) melibatkan empat dimensi, yaitu emotional arousal, composure, and formality; intimay and similarity; immediacy (liking); dan dominance-submission. Gaya hidup, kemudahan, pemangkasan waktu bahkan kecepatan dalam menyampaikan pesan telah menjadi tolak ukur bagi perkembangan manusia sebagai individu sosial yang memerlukan interaksi dengan individu lainnya.

Teknologi yang terus berkembang, manusia memanfaatkannya untuk membuat konten-konten visual kreatif untuk menyampaikan informasi dan berkomunikasi, atau disebut juga dengan komunikasi visual, dimana informasi disajikan dalam bentuk visual yang lebih menarik dan dinamis. Motion graphic merupakan sebuah tayangan audio visual berbentuk animasi yang dalam pengunaannya sering dimanfaatkan oleh suatu instansi atau perusahaan untuk penyampaian informasi yang bersifat luas seperti iklan layanan masyarakat, company profile, dan media promosi. Tidak hanya instansi atau perusahaan yang bersifat komersil yang memanfaatkan motion graphic dalam pengembangan bisnis ataupun pembaharuan sistem, dalam hal ini pun instansi pendidikan banyak melakukan inovasi dengan memanfaatkan perkembangan teknologi.

Perkembangan zaman dan perkembangan generasi zaman sekarang lebih sering menggunakan teknologi atau disebut juga dengan generasi Z. Generasi Z adalah generasi yang lahir pada rentang waktu tahun 1995 sampai tahun 2010 dalam situasi perkembangan teknologi yang pesat dimana kepribadian mereka cenderung pasif di dunia nyata dan lebih aktif di dunia maya, mereka lebih menyukai interaksi secara tidak langsung dan merasa lebih bebas dalam berekspresi di dunia maya (Stillman dan Stillman, 2018). Perkembangan media sosial yang semakin beragam dan memudahkan dalam penyebaran konten visual untuk tujuan penyebaran informasi, pesan dan juga cerita. Kementerian Komunikasi dan Informatika (Kemenkominfo) mengungkapkan pengguna internet di Indonesia saat ini mencapai 63 juta orang. Angka tersebut, 95 persennya menggunakan internet untuk mengakses jejaring sosial (kominfo.go.id). dengan ini penggunaan teknologi internet dan media sosial dapat memberikan manfaat yang begitu luas untuk berbagai kebutuhan.

Generasi millennial tidak dapat dipisahkan dari kehidupan sehari-hari tanpa sosial media. Kegiatan media sosial terdiri dari kegiatan komunikasi, 
interaksi, permainan, edukasi, bisnis, promosi serta pemasaran. Nasrullah (2015) mengartikan media sosial sebagai medium yang memungkinkan pengguna mempresentasikan dirinya maupun berinteraksi, bekerja sama, berbagi, komunikasi dengan pengguna lain, dan membentuk ikatan secara virtual. Gustina (2015) mendefinisikan sosial media sebagai bagian dari media massa versi modern yang berfungsi sebagai media online yang memiliki multifungsi interaksi.

Nasrullah (2015) menjelaskan karakteristik media sosial terdiri dari:

(1). Jaringan (network) yaitu karakter jaringan sosial yang terbangun dari struktur sosial dibentuk oleh jaringan internet. Jaringan yang terbentuk antar pengguna (user) merupakan jaingan yang secara teknologi dimediasi oleh perangkat teknologi, seperti computer, telepon genggam dan yang lainnya.

(2). Informasi (information) ialah medium yang bekerja berdasarkan informasi dan menjadi komoditas yang ada di media sosial.

(3). Arsip (archive) ialah karakter yang menjelaskan bahwa informasi telah tersimpan dan bias diakses kapan pun dan melalui perangkat apapun.

(4). Interaksi (Interactivity) ialah media sosial yang terbentuk saling mengomentari atau memberi tanda, seperti memberi tanda like pada sebuah konten.

(5). Simulasi social (Simulation of society) ialah medium yang berlangsungnya masyarakat (society) di dunia virtual.

(6). Konten oleh pengguna (User-Generated Content) ialah relasi simbiosis dalam budaya media baru yang memberikan keempatan dan keleluasaan pengguna untuk berpartisipasi.

(7). Penyebaran (Share/Sharing) ialah menyebarluaskan konten. Praktik tersebut merupakan ciri khas dari media sosial yang menunjukan bahwa khalayak aktif menyebarkan konten sekaligus mengembangkannya.

Motion graphic adalah gabungan dari potongan-potongan desain/ animasi yang berbasis media visual yang menggabungkan bahasa film dengan desain grafis dengan memasukkan sejumlah elemen yang berbeda seperti 2D/3D, animasi, video, film, tipografi, ilustrasi, fotografi, dan musik (Krishna, 2010). Krasner (2008) menjelaskan bahwa motion graphic adalah bahasa yang universal, mempunyai dampak yang lebih besar, dimana penyampaian informasi 
dalam bentuk gerakan (motion) dengan kombinasi gambar, kata - kata dan suara dapat menambah pemaknaan. Motion Graphics adalah grafik yang menggunakan footage dari video atau teknologi animasi, menciptakan ilusi dari motion atau gerakan yang dikombinasikan dengan audio untuk digunakan dalam projek multimedia (Betancourt, 2012). Adiayatama et al. (2016) menyatakan bahwa pesan pada gambar mampu memersuasi seseorang dalam menentukan sikap untuk memilih tindakan yang menunjang keinginannya.

Penelitian terdahulu pada Pratama et al. (2015) menunjukkan bahwa penggunaan media sosial telah memiliki dampak pada pola asuh dimana dijadikan sebagai bagian dari motivasi dalam mendidik anak, meskipun sentuhan secara langsung tetap dilakukan. Hal ini dipertegas Prayogi et al. (2015) menunjukkan dari hasil temuannya bahwa sistem pembelajaran berbasis ponsel pintar mampu meningkatkan kapasitas siswa dalam menerima informasi secara simultan serta memberi dampak kesenangan sehingga siswa mampu memacu dirinya untuk menggali informasi.

Penelitian yang lain menunjukkan bahwa gambar yang terdapat di instagram, bagian dari sosial media menunjukkan representasi dari tujuan pengguna dalam mempresentasikan tujuan baik promosi, pemasaran maupun perkenalan ataupun interaksi yang menunjang citra diri yang dibentuk ataupun tujuan yang ingin diharapkan (Ulfah et al. 2016). Selain itu Rijallahudin et al. (2016) aplikasi dari sebuah ponsel pintar mampu memberikan informasi dan memiliki daya impressi kepada pengguna untuk menentukan sikap dalam memutuskan. Sukrillah et al. (2017) dari penelitiannya menunjukkan bahwa terdapat fungsi media sosial sebagai jembatan promosi, hiburan, edukasi, informasi serta diskusi dalam menunjang keberlangsungan suatu intitusi.

Andjani et al. (2018) menunjukkan bahwa media sosial mampu meningkatkan kinerja suatu karyawan dalam menentukan pilihan alternatif kebutuhan dari pekerjaan yang dilakukannya. Fauziah et al. (2018) penggunaan media sosial mampu meningkatkan minat kunjungan dalam promosi wisata ke Gunung Pancar dengan berbagai titik gambar yang menarik serta kemasan animasi yang menarik. Rahmah et al. (2018) menemukan bahwa kemampuan remaja dalam penggunaan media sosial memiliki kategori yang sangat baik yang berarti memiliki keahlian yang mampu menggunakan alat tersebut sebagai hiburan namun juga untuk melakukan kegiatan yang lebih seperti halnya 
promosi dan pendidikan. Temuan selanjutnya penggunaan media memiliki karakteristik tersendiri terhadap penggunanya dalam menentukan fungsi baik sebagai promosi, informasi, pemasaran dan silaturahmi.

Temuan penelitian tersebut menjadi dasar peneliti dalam menentukan penelitian ini, sehingga tujuan dari penelitian ini adalah:

(1) mendeskripsikan manfaat motion graphic dalam media sosial;

(2) menganalisis konten promosi sekolah dalam menggunakan media sosial;

(3) menganalisis hubungan motion graphic sebagai konten promosi sekolah melalui media sosial.

\section{METODE PENELITIAN}

Metode penelitian yang digunakan adalah pendekatan asosiatif kuantitatif. Sugiyono (2015) menjelaskan penelitian asosiatif adalah penelitian yang bertujuan untuk mengetahui pengaruh atau hubungan antara dua variable atau lebih. Metode ini terdiri dari rumusan masalah, landasan teori, perumusan hipotesis, pengumulan data, analisis data, dan kesimpulan serta saran.

Pengumpulan data dilakukan dengan alat yang dinamai dengan instrumen, sehingga peneliti harus membuat dan pengembangan sendiri agar instrumen yang digunakan dapat dipercaya, maka harus melakukan uji validitas dan realibilitas. Penelitian ini memerlukan pendekatan asosiatif kuantitatif untuk mengungkapkan maupun memaparkan apa yang di temukan di lapangan dalam bentuk angka yang tersedia dalam hitungan statistika untuk menguji hubungan dari dua variabel yang diteliti.

Populasi diambil dari siswa kelas 3 SMP sebagai target promosi, aktif dalam penggunaan media sosial setiap harinya. Sekolah yang dipilih adalah:

(1). SMP Negeri 1 Ciawi,

(2). SMP Negeri 2 Ciawi,

(3). SMP Negeri 3 Ciawi,

(4). SMP Amaliah,

(5). SMP IT Fathan Mubina,

(6). SMP PGRI 1 Ciawi,

(7). SMP PGRI 2 Ciawi,

(8). SMP Wijaya Plus,

(9). SMP YPPI Ciawi, 
(10). SMP IT Roudlotul Jannah.

Populasi tersebut ditarik sampel dengan teknik Purposive Sampling. Peneliti menentukan sampel secara terpilih sebanyak 95 orang. Sampel yang terpilih diberikan kuesioner dan diuji validitas dan reabilitasnya. Setelah memperoleh data. Data dideskripsikan menggunakan artikulasi yang menunjang penjelasan data agar memiliki makna.

\section{Hasil Penelitian}

Motion graphic adalah percabangan dari seni desain graphic yang merupakan penggabungan dari, ilustrasi, tipografi, fotografi dan videografi dengan menggunakan teknik animasi. Motion graphics terdiri dari dua kata, motion yang berarti gerak dan graphics atau yang sering kita kenal dengan istilah grafis. Motion graphic juga dapat disebut dengan istilah grafis gerak. Motion graphic pada umunnya merupakan gabungan dari potongan-potongan desain yang berbasis media visual yang menggabungkan bahasa film dengan desain grafis, seperti memasukan elemen-elemen yang berbeda seperti desain $2 d$ atau $3 d$, animasi, video, tipografi, ilustrasi, fotografi, dan musik.

Unsur-unsur disain grafis yang diberi gerakan dengan teknik animasi dapat memberikan kesan yang menarik dan dapat menarik perhatian lebih kepada siapapun yang melihatnya. Sebuah gambar yang bergerak, sebuah teks yang bergerak, dipadukan dengan penggunaan warna yang menarik dan audio/suara yang tepat dapat menambah pemaknaan sebuah media informasi. Motion graphic memiliki dampak yang lebih besar dalam komunikasi visual, dimana penyampaian informasi dalam bentuk gerakan (motion) dengan kombinasi gambar, kata-kata dan suara dapat menambah pemaknaan (Krasner, 2008). Motion graphic digunakan untuk berbagai kepentingan, seperti periklanan, khususnya untuk media elektronik, baik media televisi maupun media internet, opening sebuah program televisi, video clip musik serta profil sebuah perusahaan atau instansi.

Motion graphic merupakan konten digital yang dapat dengan mudah disebarluaskan melalui jaringan media sosial, penyebaran informasi promosi ke khalayak umum dan juga yang menjadi target promosi. Penggunaan media motion graphic sebagai media promosi dirasa sangat efisien, didukung dengan kemudahan berbagi (sharing) di internet. Hal ini salah satu alternatif promosi 
yang dapat dilakukan. Motion graphic dapat digunakan sebagai media untuk presentasi maupun sebagai konten untuk disebar dalam media sosial yang dimiliki oleh sekolah. Motion graphic mampu memengaruhi minat anak-anak SMP yang sedang mencari sekolah untuk melanjutkan pendidikan.

Karakteristik motion graphic yang informatif, menarik dan juga menghibur dengan adanya konten visual seperti gambar, teks dan diberi warnawarna yang dapat menarik, ditambah dengan suara dan musik yang dapat mengubah suasana hati, dipadukan dengan gerakan (motion) memberikan kesan dinamis, dapat menambah pemaknaan dan efektifitas atas informasi yang disampaikan. Ditambah dengan penggunaan media sosial sebagai medium untuk penyebaran konten yang hampir setiap orang di Indonesia untuk berbagai kebutuhan.

Data penelitian menunjukkan bahwa motion graphic mampu menyihir kaula muda dalam penggunaan media sosial dan berkreasi dalam seni digital. Penampakan Tabel 1 menggambar bahwa setiap responden mampu menggunakan motion graphic dan menjadi daya tarik mereka dalam melihat informasi.

Tabel 1. Penilaian responden terhadap instrument motion graphic

\begin{tabular}{|l|c|c|}
\hline \multicolumn{1}{|c|}{ Motion Graphic } & Penilaian (Persentase) & Makna \\
\hline Gambar & 88 & Menarik minat \\
\hline Teks & 84 & Menarik minat \\
\hline Warna & 85 & Menarik minat \\
\hline Suara & 68 & Kurang menarik minat \\
\hline Animasi & 90 & Menarik minat \\
\hline Gabungan & 83 & Menarik Minat \\
\hline
\end{tabular}

Keterangan:

0-25: Kurang menarik, 26-50: Biasa, 51-75: Menarik, 76-100: Sangat Menarik

Tabel 1 di atas, menunjukkan bahwa animasi mampu menarik minat kaulamuda dalam menciptakan kreasi di media sosial. Selain itu, gambar, teks, warna adalah nilai yang tertinggi dalam menciptakan motion motion graphic. 
Hanya suara yang kurang memiliki daya tarik terhadap fungsi motion graphic, ini disebabkan adanya kurang variasi graphic dalam suara. Adiayatama et al. (2016) menjelaskan bahwa gambar, teks, warna memiliki nilai visual yang menarik penglihatan pengguna dibanding audio. Kemampuan melihat seseorang memiliki dua kali lebih cepat dibanding dengan pendengaran. Sehingga kemampuan visual sangat memiliki pengaruh terhadap daya keterdedahan informasi.

Penggunaan motion graphic memiliki nilai atraktif, edukatif, interaktif dan informatif dimana memfokuskan pada bentuk, warna, tekstur dan cahaya (Wulandari et al. 2015). Sedangkan nilai dari manfaat motion graphic terbagi atas informasi, persuasi, afeksi, edukasi dan pengambilan keputusan. Adapun tabulasi silang dari motion graphic dan manfaat motion graphic ditampakkan pada Tabel 2 .

Tabel 2 Manfaat motion graphic terhadap fungsi dari motion

\begin{tabular}{|l|c|c|c|c|c|c|}
\hline Manfaat Motion Graphic & Gambar & Teks & Warna & Suara & Animasi & Gabungan \\
\hline Informasi & 70 & 62 & 72 & 80 & 80 & 73 \\
\hline Persuasi & 86 & 80 & 83 & 85 & 80 & 83 \\
\hline Afeksi & 80 & 73 & 78 & 75 & 80 & 77 \\
\hline Edukasi & 80 & 73 & 78 & 78 & 79 & 78 \\
\hline Pengambilan keputusan & 79 & 72 & 78 & 80 & 80 & 77 \\
\hline
\end{tabular}

Keterangan:

0-25: Kurang Baik

26-50: Biasa

51-75: Baik

76-100: Sangat Baik

Tabel 2 menunjukkan minat bahwa penggunaan motion graphic mampu membangkitkan afeksi dan pengambilan keputusan untuk mengikuti pesan yang disampaikan, meskipun informasi yang disampaikan kurang menjadi sasaran personal pengguna media sosial. Fauziah et al. (2018) menunjukkan pada temuannya bahwa kemampuan grafis dalam mempromosikan dan membangun persuasi seseorang sangat ampuh mengajak untuk berperan serta. Pengembangan persuasi ini sejalan dengan minat remaja untuk senantiasa mencoba dan mencari tahu dalam hal teknologi yang kekinian dan membawa 
kepada aras pengetahuan digital remaja. Media sosial tanpa motion graphic menjadi hambar alias statis, sehingga media sosial yang mengandung motion graphic akan memiliki peminat dan pengguna yang terhibur.

Media promosi memiliki informasi tentang sekolah, seperti visi misi sekolah, sarana dan prasarana sekolah, program yang dijalankan oleh sekolah, jumlah siswa, daftar ekstrakulikuler, dan berbagai keunggulan lainnya yang dimiliki oleh sekolah tersebut. Informasi disajikan dalam bentuk audiovisual, yang terdiri dari unsur visual seperti gambar, teks, dan warna serta dipadukan dengan gerakan dan suara. Dengan karakteristik motion graphic yang informatif dan dinamis, dapat menambah pemaknaan dan efektifitas atas informasi yang disampaikan. Hasil rekapitulasi responden konten promosi dapat dilihat pada Tabel 3 berikut ini:

Tabel 3. Rekapitulasi konten promosi

\begin{tabular}{|l|c|c|}
\hline Konten Promosi & Nilai (Persentase) & Makna \\
\hline Visual & 86 & Lebih menarik, impressi yang kuat \\
\hline Animasi & 83 & Lebih menarik, Kreativitas yang unik \\
\hline
\end{tabular}

Keterangan:

$0-25$ : Kurang menarik

26-50: Biasa

51-75: Menarik

76-100: Sangat Menarik

Berdasarkan hasil rekapitulasi pada Tabel 3 motion graphic dalam konten promosi mendapatkan nilai $84,5 \%$ yang menurut penafsiran berada dalam katagori sangat baik. Dimensi visual mendapat nilai rata-rata sebesar $86 \%$ dengan katagori sangat baik. Visual terdiri dari gambar, teks, warna serta bentuk yang mampu menarik remaja untuk mempelajari pesan baik dalam bentuk teknik pengerjaannya maupun pesan yang disampaikannya. Sedangkan animasi memiliki nilai 83\% dengan kategori sangat baik dimana daya tarik dan kreativitas pembuat memberikan kesan positif terhadap remaja yang melihatnya. Hal ini menjadi bentuk promosi yang baik dan memiliki jangkauan yang luas terhadap kalangan remaja.

Konten visual memudahkan dalam mencari informasi, menunjukan bahwa gambar dapat menyampaikan informasi lebih baik dan mudah untuk 
dipahami. Teks dapat memberi lebih banyak informasi dan media yang universal digunakan untuk penyampaian pesan, walau terkadang di zaman sekarang teks yang terlalu banyak dapat menyebabkan efek jenuh. Warna membuat ketertarikan yang sesuai dengan kepribadian seseorang.

Konten animasi menunjukan bahwa gambar bergerak menjadi sesuatu yang sangat menarik perhatian responden. Tayangan yang sesuai dengan usia responden menunjukan bahwa animasi sesuai dengan responden dengan kategori remaja, namun animasi juga masih bisa dikatagorikan sebagai tayangan untuk segala usia. Selain itu, Animasi mudah diingat mendapat dengan suara yang menarik. Selain itu, dukungan backsound musik dapat merubah suasana hati, menunjukan bahwa musik dapat memengaruhi suasana hati. Sehingga dengan berbagai tayangan dengan menampilkan karakter kartun yang digabung dengan backsound music dapat membuat responden terhibur.

Motion graphic adalah sebuah tayangan mampu memberikan informasi yang lebih menarik, informatif dan menghibur. Penggunaan unsur-unsur visual yang dipadukan dengan suara dan gerakan (motion) dapat menambah pemaknaan dari sebuah isi pesan. Krasner (2008) menunjukkan bahwa perpaduan konten promosi berupa animasi dan visual mampu memberikan daya imaginasi bagi remaja dalam memaknai sebuah pesan secara langsung dan memiliki makna yang lebih lama.

Perkembangan media sosial yang semakin beragam dan memudahkan dalam penyebaran konten visual untuk tujuan penyebaran informasi, pesan dan juga cerita. Penggunaan teknologi internet dan media sosial dapat memberikan manfaat yang begitu luas untuk berbagai kebutuhan terutama untuk media promosi sekolah. Motion graphic memengaruhi minat remaja dalam memilih sekolah, tayangan, hobi dan pilihan lainnya yang digunakan sebagai ajang promosi bagi produk yang menyasar bagi kalangan remaja.

Hasil olahan data Rank Spearman antara variabel media motion graphic dalam media sosial (X) terhadap konten promosi sekolah (Y) sebesar 0.323 dengan tingkat signifikansi $0.01(\mathrm{p}>0,05)$. Faktor penggunaan media motion graphic berpengaruh terhadap konten promosi sekolah kepada peserta didik baru dengan tingkat hubungan sangat kuat. Hasil uji statistik menunjukkan adanya pengaruh kuat yang disajikan dalam Tabel 4 berikut ini: 
Tabel 4. Analisa motion graphic dalam media sosial terhadap bentuk konten promosi sekolah

\begin{tabular}{|l|l|c|l|}
\hline \multirow{2}{*}{ Spearman rho } & Korelasi & Sig (2-Tailed) & Makna \\
\cline { 2 - 4 } & \multicolumn{3}{|c|}{ Konten promosi sekolah } \\
\hline $\begin{array}{l}\text { motion graphic } \\
\text { dalam media } \\
\text { sosial }\end{array}$ & $0,323^{* *}$ & 0,001 & $\begin{array}{l}\text { Hubungan } \\
\text { Kuat }\end{array}$ \\
\hline
\end{tabular}

Keterangan: **Signifikan pada taraf $1 \%$

Pada hasil uji hipotesis menunjukan bahwa ada hubungan yang signifikan antara media motion graphic terhadap konten promosi sekolah dengan ditunjukkan pada minat siswa SMP kelas 3, yang ditunjukan dari hasil uji signifikansi yaitu 3.476, jika dibandingkan dengan nilai $t_{\text {tabel }}$ dari jumlah (n) 95 sebesar1.665, maka thitung $>t_{\text {tabel }}$ yang artinya $\mathrm{H}^{\mathrm{o}}$ ditolak dan $\mathrm{H}^{\mathrm{a}}$ diterima, dengan demikian terdapat hubungan yang signifikan antara motion graphic dengan konten promosi sekolah sebagai daya tarik minat siswa. Sedangkan pada nilai korelasi sebesar 0,323 artinya media motion graphic memenuhi kriteria sebagai pengaruh terhadap konten promosi sekolah dengan tingkat hubungan yang tinggi. Adapun pengaruh yang diberikan pada uji koefisien diterminasi oleh Variabel X (motion graphic) terhadap variabel Y (konten promosi sekolah) adalah sebesar $10.4 \%$ sesuai dengan hasil perhitungan koefisien determinasi. Hal ini berarti masih kurangnya konten promosi sekolah yang digunakan sebagai ajang promosi untuk menarik minat siswa.

Penelitian terdahulu menunjukkan bahwa Fauziah et al. (2018) menjelaskan bahwa promosi secara media sosial mampu membangun korelasi yang kuat terhadap pelanggan untuk kekinian dalam membangun informasi. Motion graphic dalam promosi merupakan cara kekinian dalam membangun konsep promosi masih banyak konsep promosi yang dapat dibangun secara digital baik secara animasi maupun secara visual atau gabungan (motion graphic). 


\section{Kesimpulan}

1. Motion grapich adalah sebuah media penyampaian informasi yang lebih menarik dan informatif, karena pesan dapat dikemas dengan lebih dinamis dengan unsur audio dan visual.

2. Konten promosi sekolah memberikan pengaruh yang positif terhadap kalangan remaja penerima konten khususnya siswa yang akan melanjukan pendidikan ke tingkat selanjutnya.

3. Motion graphic di media sosial memiliki hubungan terhadap konten promosi sekolah sehingga menjadi bagian dari medium promosi.

\section{Saran}

1. Motion graphic tidak dapat sepenuhnya dijadikan media utama dalam kegiatan promosi, penggunaan media konvensional seperti brosur, spanduk, dan yang lainnya sebagai pelengkap informasi, karena mengingat kelemahan motion graphic yang tidak dapat menampun informasi yang terlalu banyak.

2. Penyesuaian konten harus dilakukan agar sesuai dengan target audien yang dituju, baik secara umur maupun latarbelakang audiens, agar tidak ada kesalahan akibat kesalahan dalam penyajian konten.

3. Penggunaan media sosial dan internet dalam penyebaran konten motion graphic dapat membantu dalam penyebaran informasi yang lebih luas dan efektif.

\section{DAFTAR PUSTAKA}

Adiayatama I, Suryatna U, Kusumadinata AA. 2016. Pengaruh Pesan Gambar Peringatan Bahaya Merokok Terhadap Perubahan Prilaku Perokok. Jurnal Komunikatio 2 (1): 67-95.

Andjani A, Ratnamulyani IA, Kusumadinata AA. 2018. Penggunaan Media Komunikasi Whatsapp terhadap Efektivitas Kinerja Karyawan. Jurnal Komunikatio. 4 (1): 41-50.

Betancourt, Michael. 2012. The Origins of Motion Graphics, Cinegraphic, (online), Diakses pada tanggal 5 Juni 2018 dari (http://www.cinegraphic.net/article.php?story=20110826144209282).

Gustina H. 2015. Korelasi Media Sosial Instagram dengan Presentasi Diri Mahasiswa Jurusan Ilmu Komunikasi Universitas Riau. Jom FISIP. 2 (2): $1-15$. 
Fauziah R, Ratnamulyani IA, Kusumadinata AA. 2018. Efektifitas Promosi

Destinasi Wisata Rekreasi Gunung Pancar Melalui Postingan Instagram Media Sosial. Jurnal Komunikatio. 4(1): 27-40

Krasner, John. 2008. Motion Graphic Design Applied History and Aesthetics. Burlington (UK): Focal Press.

Krishna. 2010. Motion by Design Magazine, (online), Diakses pada tanggal 6 Juli 2018 dari (https://issuu.com/motionbydesign/docs/mbd1).

Littlejohn, Stephen \& Karen Foss. 2014. Teori Komunikasi. Jakarta (ID): Salemba Humanika.

Nasrullah, Rulli. 2015. Media Sosial Perspektif Komunikasi, Budaya, dan Sosioteknologi. Bandung (ID): Simbosa Rekatama Media

Pratama DR, Ratnamulyani IA, Fitriah M. 2015. Pengaruh Sosial Media Komunikasi Interpersonal Ibu 2dan Anak dalam Membangun Motivasi Belajar. Jurnal Komunikatio. 1(2): 115-134.

Prayogi R, Suryatna U, Kusumadinata AA. 2015. Hubungan Komunikasi Pembelajaran Sistem E-Learning dengan Motivasi Belajar. Jurnal Komunikatio. 1 (2): 99-113.

Rahmah M, Sukarelawati, Fitriah Maria. 2018. Hubungan antara Kecenderungan Mahasiswa Menggunakan Jenis Aplikasi Gadget dengan Kepekaan Sosial. Jurnal Komunikatio. 4(2): 83-96.

Rijallahudin, Ratnamulyani IA, Kusumadinata AA. 2016. Pengaruh Penggunaan Layanan Aplikasi Digital Google Play Terhadap Pemenuhan Kebutuhan Informasi Responden. Jurnal Komunikatio. 2 (2): 135-146.

Stillman, David \& Jonah Stillman. 2018. Generasi Z: Memahami Karakter

Generasi Baru Yang Akan Mengubah Dunia Kerja. Jakarta (ID):

Gramedia Pustaka Utama.

Sugiyono. 2015. Metode Penelitian Kuantitatif, Kualitatif dan R\&D. Bandung (ID): Penerbit Alfabeta.

Sukrillah S, Ratnamulyani IA, Kusumadinata AA. 2017. Pemanfaatan Media Sosial Melalui Whatsapp Group Fei Sebagai Sarana Komunikasi. Jurnal Komunikatio. 3(2): 95-104.

Ulfah R, Ratnamulyani IA, Fitriah M. 2016. Fenomena Penggunaan Foto Outfit Of the Day di Instgram Sebagai Media Presentasi Diri (Suatu Kajian Komunikasi Dalam Pendekatan Dramaturgi Erving Goffman). Jurnal 
Komunikatio. 2 (1): 1-14.

Wulandari H, Kusumarini Y, Suryanata L. 2015. Perancangan Interior "Five Sense" di Surabaya. Jurnal Intra. 3 (2): 167-175. 